\title{
Effect of Trace Addition of Ag on the Precipitation Behavior of Al-Mg-Cu Alloy
}

\author{
Mami Mihara ${ }^{1, a}$, Equo Kobayashi ${ }^{1, b}$, and Tatsuo Sato ${ }^{2, c}$ \\ 1 Department of Metallurgy and Ceramics Science, Tokyo Institute of Technology, Tokyo 152-8552, Japan \\ 2 Precision and Intelligence Laboratory, Tokyo Institute of Technology, Yokohama 226-8503, Japan \\ E-mail: amihara.m.aa@m.titech.ac.jp, bequo@mtl.titech.ac.jp, ${ }^{c s a t o @ m t l . t i t e c h . a c . j p ~}$
}

\begin{abstract}
Effect of $\mathrm{Ag}$ addition on the age-hardening response and precipitate microstructure of the $\mathrm{Al}-3.0 \mathrm{Mg}-1.0 \mathrm{Cu}(\mathrm{wt} \%)$ alloy has been investigated by micro Vickers hardness and transmission electron microscopy (TEM). The alloy compositions located in the $(\alpha+\mathrm{S}+\mathrm{T})$ phase field of the $\mathrm{Al}-\mathrm{Mg}-\mathrm{Cu}$ phase diagram are known to be effective to harden in two stages separated by a distinct and often prolonged hardness plateau. The first stage of hardening occurs very rapidly (e.g. within $60 \mathrm{~s}$ at $443 \mathrm{~K}$ ) and contributes to increase the hardness as much as $50 \%$ of the total age-hardening. Trace addition of Ag changes the age hardening response of the $\mathrm{Al}-3.0 \mathrm{Mg}-1.0 \mathrm{Cu}$ alloy dramatically. In the $\mathrm{Ag}$ added alloy, the hardness change during the first stage of hardening is larger and the plateau stage is shortened as a result of the fast arrival at the second stage of hardness. The microstructure at the plateau stage of hardening for the Al-3.0Mg-1.0Cu alloy exhibits no clear evidence of any precipitates contributing to the first rapid hardening. On the other hand, lath-shaped S phase was observed at the peak hardness. In the Ag-added alloy, fine distributed precipitates were obtained from the beginning of age-hardening.
\end{abstract}

Keywords: Aluminium-magnesium-cupper alloy, silver addition, age-hardening, microalloying, precipitate, transmission electron microscopy (TEM).

ENGINEERING JOURNAL Volume 19 Issue 3

Received 27 May 2015

Accepted 27 May 2015

Published 5 June 2015

Online at http://www.engj.org/

DOI:10.4186/ej.2015.19.3.75 


\section{Introduction}

It has been essential to consider ecology in industry, e.g. reducing $\mathrm{CO}_{2}$ exhaust and saving natural resources, when a factory makes products. Among several materials, aluminium alloys have been widely utilized because of their major advantages, such as low density, good corrosion resistance and good formability. Applications of aluminum products are increasing with time and expected to be enlarged worldwide in the future. In several aluminum products, transportation components are in a great demand. Al-Mg alloys have been utilized as a light-weight body sheet material for automobiles due to their well-balanced properties of mechanical strength, ductility and press-formability. Although these alloys are non-heat treatable, their strength can be increased by the addition of copper because $\mathrm{Al}-\mathrm{Mg}-\mathrm{Cu}$ alloys give rise to precipitation strengthening phenomena [1]. This improvement partially meets the requirement of manufacturing processes in which good age-hardenability during a paint-bake treatment at $\sim 170{ }^{\circ} \mathrm{C}$, termed as a bakehardening (BH) response (Fig. 1), is favorable to prevent "bake-softening" occurring in Al-Mg alloys. Aside from the more numerous studies of $\mathrm{Al}-\mathrm{Cu}-\mathrm{Mg}$ alloys, some attention has also been paid to the $\mathrm{Al}-\mathrm{Mg}-\mathrm{Cu}$ alloys (closely related to 5000 series aluminum alloys). Recently, Ringer et al. have investigated the agehardening response of $\mathrm{Al}-\mathrm{Mg}-\mathrm{Cu}$ alloys. $\mathrm{Al}-\mathrm{Mg}-\mathrm{Cu}$ alloys are suitable for body sheet material for automobiles, although their commercialization has been limited due to the fact that their tensile strength are no greater than alloys containing less $\mathrm{Mg}$ at $150-200^{\circ} \mathrm{C}$. The age-hardening characteristics are very similar to those for the alloys containing less $\mathrm{Mg}$ and little work has been completed on the $\mathrm{Al}-\mathrm{Mg}-\mathrm{Cu}$ alloys to take advantage of them. According to the classical studies [2-3], the strengthening of $\mathrm{Al}-\mathrm{Mg}-\mathrm{Cu}$ alloys is based on a precipitation hardening through the sequence as follows:

$$
\alpha(\mathrm{SSSS}) \rightarrow \mathrm{Cu} / \mathrm{Mg} \text { nanoclusters } \rightarrow \mathrm{GPB} \text { zones }\left(\mathrm{S}^{\prime}\right) \rightarrow \mathrm{S}^{\prime} \rightarrow \mathrm{S}\left(\mathrm{Al}_{2} \mathrm{CuMg}\right) .
$$

where SSSS is the supersaturated solid solution. $\mathrm{Cu} / \mathrm{Mg}$ clusters are considered as precursors to the Guinier-Preston-Bagaryatsky (GPB) zones. In $\mathrm{Al}-\mathrm{Mg}-\mathrm{Cu}$ alloys, hardening occurs in two distinct stages separated by a plateau. The first stage of hardening occurs very rapidly (e.g. within 1 min at $170{ }^{\circ} \mathrm{C}$ ) and contributes to increase hardness as much as $60 \%$ of the total age-hardening. The small addition of some alloying elements has been recognized to be effective to control precipitate microstructures and alloy properties [4-7]. According to the several works, the small addition of $\mathrm{Ag}$ is extremely effective to improve age-hardening response of the $\mathrm{Al}-\mathrm{Mg}-\mathrm{Cu}$ alloy [8-10] although the detail has not been investigated. The objective of this study is to gain understanding about the precipitates forming in $\mathrm{Al}-\mathrm{Mg}-\mathrm{Cu}(-\mathrm{Ag})$ alloys and the effect of $\mathrm{Ag}$ addition by means of hardness measurements and transmission electron microscopy (TEM) investigations in order to achieve high mechanical property.

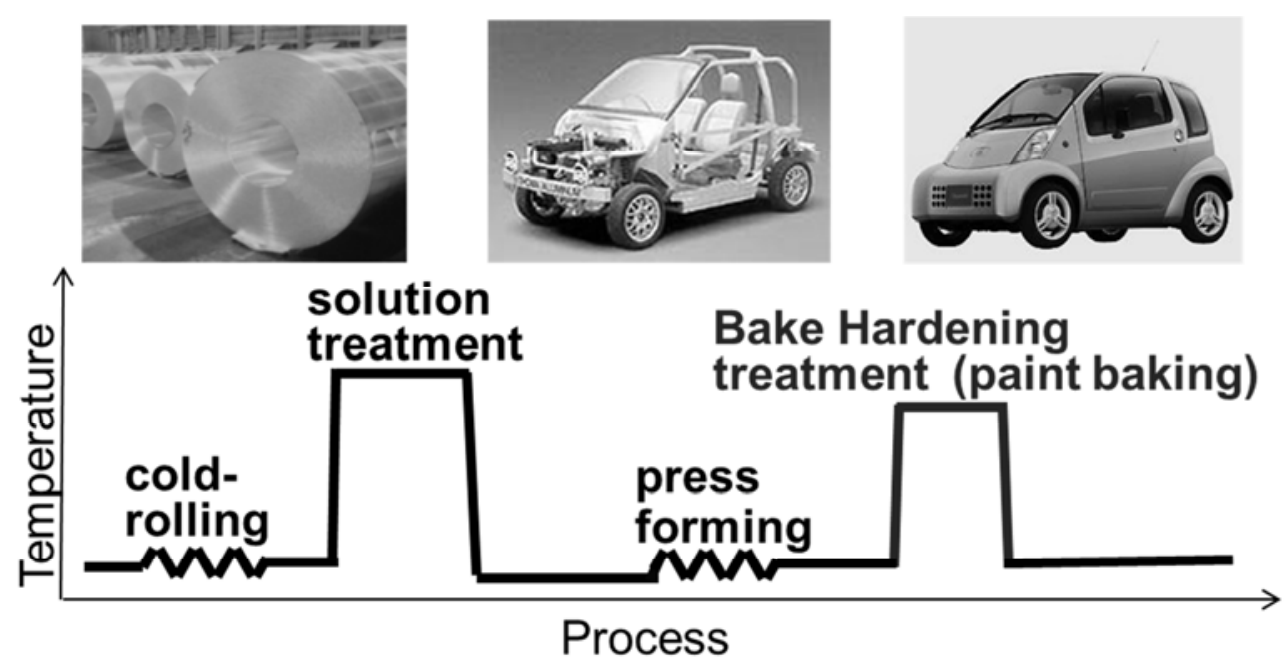

Fig. 1. A example of schematic illustration of manufacturing process of automobiles. 


\section{Experimental}

Two alloys named as Base and Ag-added are used in this study. Their chemical compositions are listed in Table 1. The specimens were solution treated in a salt bath at $520{ }^{\circ} \mathrm{C}$ for $0.6 \mathrm{ks}$, followed by iced-water quenching and kept for $60 \mathrm{~s}$. These specimens are called as as-quenced (A.Q.) alloys in this paper. The artificial aging treatment was carried out in an oil bath at $170{ }^{\circ} \mathrm{C}$ for various times. Schematic illustration of heat treatment process is shown in Fig. 2. After aging treatment, micro Vickers hardness was measured with a load of $500 \mathrm{~g}$ for $15 \mathrm{~s}$ using Mitsutoyo HM-102. Differential scanning calorimetry (DSC) was carried out using a Rigaku equipment of DSC8230 with $40 \mathrm{mg}$ of pure $\mathrm{Al}(99.99 \%)$ as a reference under an argon atmosphere with a heating rate of $0.167 \mathrm{~K} / \mathrm{s}$. The range of temperature for the DSC measurement was set from 223 to $773 \mathrm{~K}$ using a liquid nitrogen controller. Electrical resistivity measurements were also performed by a four-probe method with the specimens prepared as wires with the diameter of $1.0 \mathrm{~mm}$ and the gage length of $300 \mathrm{~mm}$. Precipitate microstructure was investigated by TEM in bright-field mode using Philips CM30 operated at $150 \mathrm{kV}$ with a double-tilt holder.

Table 1 Chemical compositions of alloys in $\mathrm{wt} \%$.

\begin{tabular}{cccccccc}
\hline Alloy / Element (wt\%) & $\mathrm{Mg}$ & $\mathrm{Cu}$ & $\mathrm{Ag}$ & $\mathrm{Si}$ & $\mathrm{Fe}$ & $\mathrm{Ti}$ \\
\hline Base alloy & 3.04 & 1.01 & - & 0.01 & 0.01 & 0.00 \\
\hline Ag-added alloy & 3.05 & 0.99 & 0.41 & 0.00 & 0.00 & 0.00 \\
\hline \multicolumn{1}{c}{5} \\
\end{tabular}

Fig. 2. Schematic illustration of heat treatment process

\section{Results}

\subsection{Hardness Changes During Aging}

The results of micro Vickers hardness changes during aging at $170{ }^{\circ} \mathrm{C}$ are shown in Fig. 3. In both alloys, a marked increase of the hardness occurs in the initial stage, the first stage of hardening, and then, the hardness remains almost constant for a long time, the plateau stage, finally, the hardness reaches the peak, the second stage of hardening. In the Ag-added alloy, the hardness change during the first stage of hardening is larger and the plateau stage is shortened as a result of the fast arrival at the second stage of hardening. Trace addition of Ag is extremely effective to improve the age-hardening response of the Base alloy. 


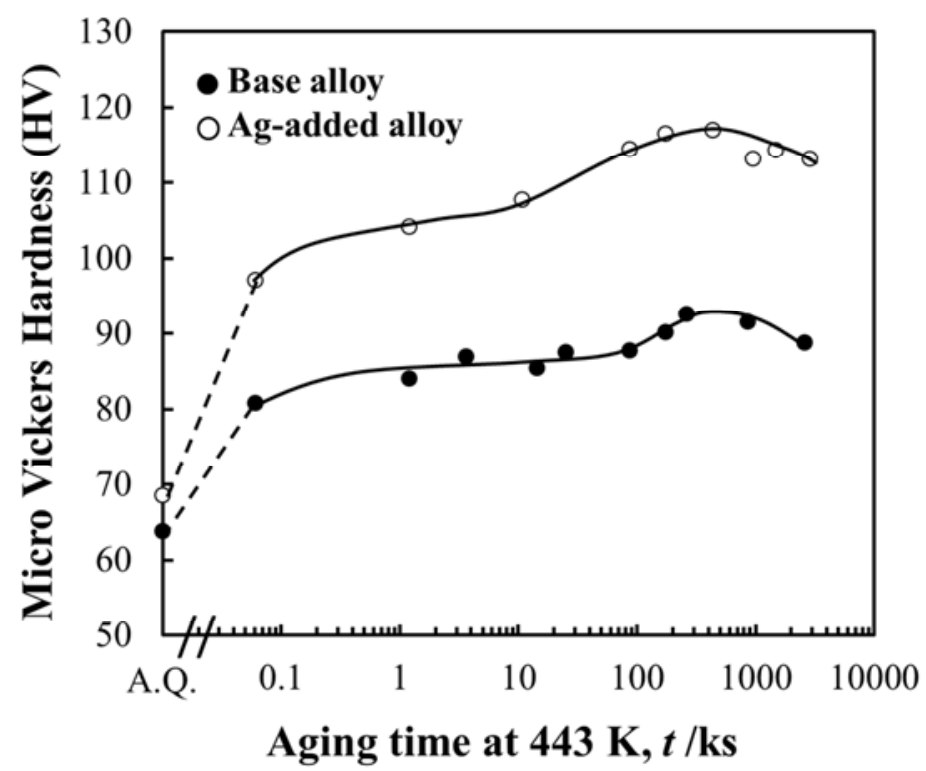

Fig. 3. Age-hardening response for the Base and Ag-added alloy aged at $170^{\circ} \mathrm{C}$.

\subsection{Electrical Resistivity Increment During Aging}

The precipitation behavior of $\mathrm{Al}-\mathrm{Mg}-\mathrm{Cu}(-\mathrm{Ag})$ alloys can be followed by DSC as well as electrical resistivity measurements. Electrical resistivity is sensitive to microstructures of an alloy, even if the thermal reaction is small. Figure 4 shows the electrical resistivity increment, $\Delta \rho$, during aging at $443 \mathrm{~K}$ in both alloys. Although various elements affect the electrical resistivity, the electrical resistivity, $\rho$, of alloys containing solute elements, GP zones or precipitates is generally described by the following equation.

$$
\rho=\rho_{0}+\rho_{s}+\rho_{p}
$$

$\rho 0$ is the contribution to the electrical resistibility due to the phonon scattering in aluminum. $\rho \mathrm{s}$ is the residual resistance of the solute atoms in the matrix. $\rho \mathrm{p}$ is the contribution to the electrical resistivity by precipitates. Since $\rho 0$ is originated in the lattice vibration of aluminum, it does not change during isothermal aging treatment only depending on temperature. $\mathrm{es}$ is dependent on the solute concentration in the matrix. Since the solute concentration decreases with the progress of the phase decomposition, this value decreases with aging time, and if it reaches the balanced solute concentration at the temperature, it will turn into a certain value. Although $\varrho p$ is 0 in a perfect supersaturated solid solution, it changes with the formation of solute clusters and is given by the product of a function of the number density $\mathrm{N}$ and size $\mathrm{D}$, G (D).

$$
\rho_{p}=N \cdot G(D)
$$

Since the contribution by the increase in the number density of clusters and GP zones is large in the early stage of the phase decomposition, electrical resistivity dramatically increases and then, the number density of GP zones markedly decreases, resulting in the decrease in the resistivity even the average size becomes increased. Then, the electrical resistivity change generally shows a maximum by those balances.

Electrical resistivity increment during aging at $443 \mathrm{~K}$ has good agreement with the change of hardness (Fig. 3). Since the contribution by the increase in the number density of nanoclusters and GP zones is large in the early stage of aging, electrical resistivity dramatically increases. Then the number density of GP zones markedly decreases resulting in the decrease in the resistivity even the average size of the GP zones becomes large. Finally, the electrical resistivity change generally shows a maximum by the balance of those factors. The rapid fall of resistibility after prolonged aging is due to the formation and growth of precipitates. Time to maximum resistivity is reduced by small addition of Ag. In Ag-added alloy, the resistivity falls more rapidly comparing to Base alloy. 


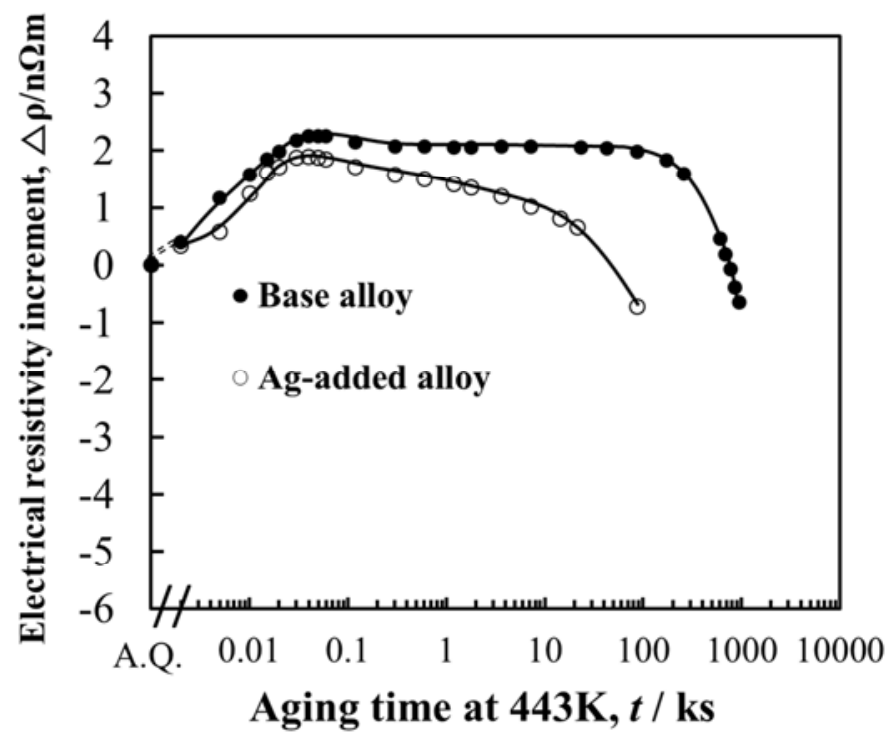

Fig. 4. Electrical resistivity increments for the Base and Ag-added alloys aged at $443 \mathrm{~K}$.

\subsection{DSC Analysis}

DSC is an analytical technique that enables the heat effects associated with transformation reactions in a material to be detected. The analysis is an appropriate method to determine the precipitation and dissolution reactions in the as-quenched and aged conditions of the alloy. Figure 5 shows a process of DSC measurement. By using DSC method, heat flow curves are obtained. The precipitation behavior of Al-Mg$\mathrm{Cu}$ alloys can be followed by DSC as well as electrical resistivity measurements. Electrical resistivity is sensitive to microstructures of an alloy, even if the thermal reaction is small. On the other hand, by using DSC method, the number, positions and the area of the peaks are obtained. Those factors are related to the formation rate of precipitates, the types of precipitates and the amount of precipitates which are formed during heating by DSC.

DSC curves for the Base and Ag-added alloys aged at $170^{\circ} \mathrm{C}$ for various times are shown in Fig. 6 . During heating subsequently after water quenching, exothermal peak (peak A) appears at around $370 \mathrm{~K}$ in both alloys. It suggests that nanoclusters are formed during heating by DSC. In both alloys, this peak is disappeared after aging treatment for $5 \mathrm{~min}$ at $170^{\circ} \mathrm{C}$. Since nanoclusters are already formed after aging treatment for $5 \mathrm{~min}$, peak A is not observed during heating by DSC.

(a)

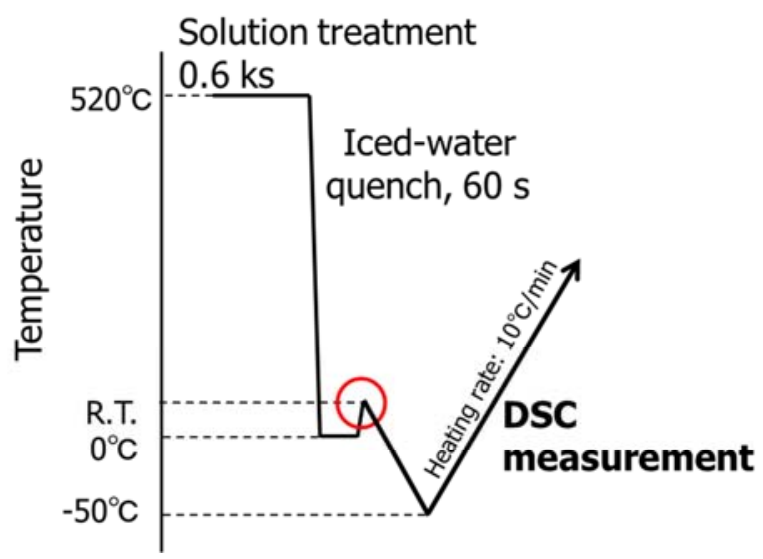

(b)

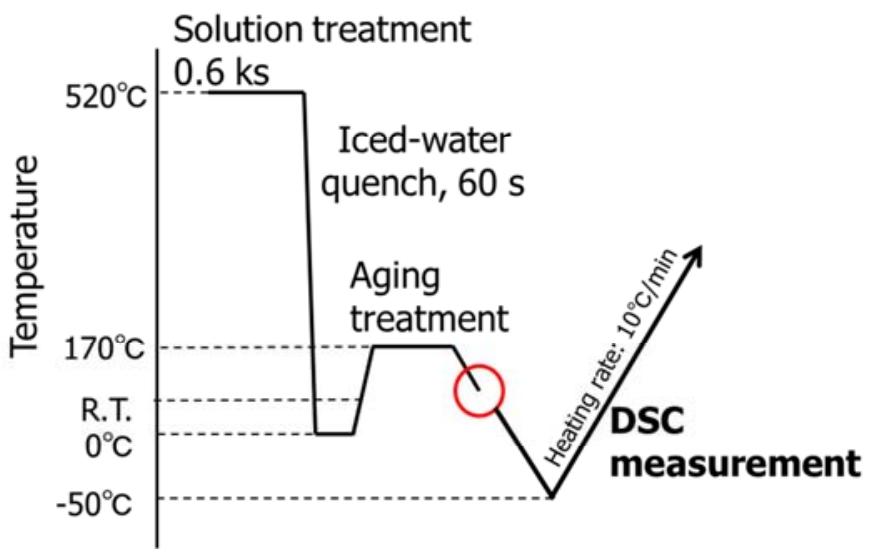

Fig. 5. DSC measurement process for (a)as-quenched and (b) aged at $443 \mathrm{~K}$ alloys. 
(a)

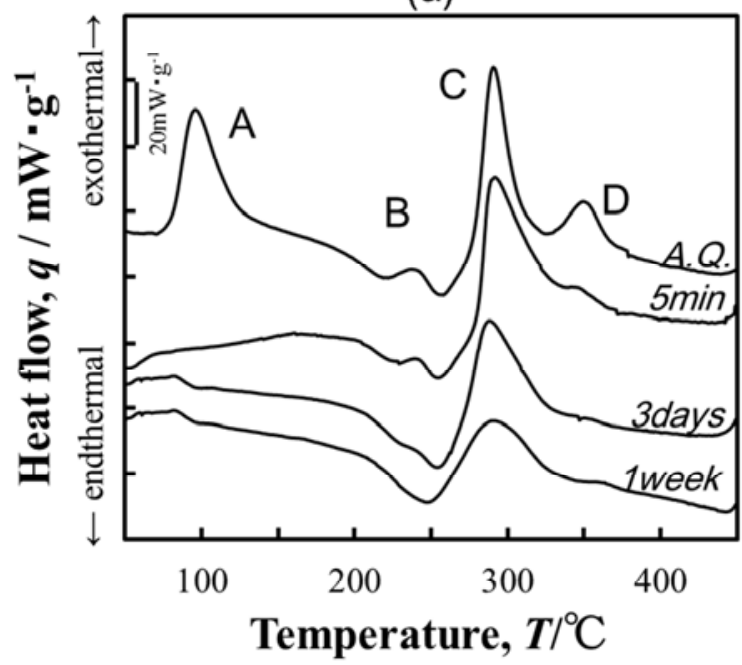

(b)

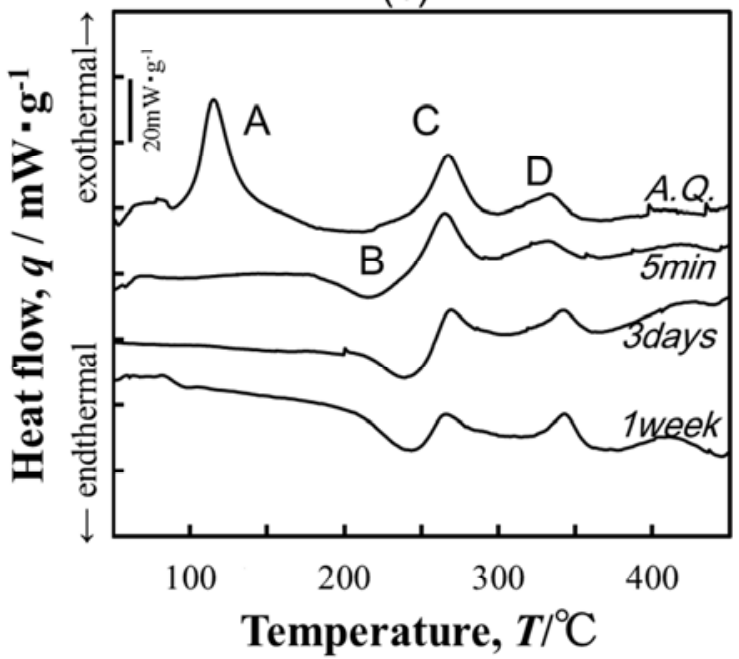

Fig. 6. DSC curves for the (a) Base and (b) Ag-added alloys aged at $443 \mathrm{~K}$.

Table 2 Summary of each peaks obtained from DSC curves.

\begin{tabular}{|c|c|c|c|c|}
\hline Alloy/peak & A & B & C & D \\
\hline Base alloy & $\begin{array}{c}\text { Formation of } \\
\text { nanoclusters }\end{array}$ & $\begin{array}{c}\text { Dissolution of } \\
\text { nanoclusters }\end{array}$ & $\begin{array}{c}\text { Formation of } \\
\text { Z phase }\end{array}$ & $\begin{array}{c}\text { Formation of } \\
\text { S phase }\end{array}$ \\
\hline Ag-added alloy & $\begin{array}{l}\text { Formation of } \\
\text { nanoclusters }\end{array}$ & $\begin{array}{c}\text { Dissolution of } \\
\text { nanoclusters }\end{array}$ & $\begin{array}{c}\text { Formation of } \\
\text { T phase }\end{array}$ & $\begin{array}{c}\text { Formation of } \\
\text { S phase }\end{array}$ \\
\hline
\end{tabular}

The size of Peak A of the Base alloy is more pronounced than that of the Ag-added alloy in the asquenched condition, resulting in that the size of Peak $\mathrm{C}$ of the Base alloy is more pronounced than that of the Ag-added alloy. Furthermore, the position of peak A is shifted to higher temperature in the Ag-added alloy. It is suggested that the formation of nanoclusters is delayed and the amount of nanoclusters is reduced by Ag-addition. However, in the Ag-added alloy, hardness increment in the initial stage of hardening is much larger than that of the Base alloy. Accordingly, although the amount of nanoclusters is reduced, different type of nanoclusters which is more effective to increase hardness is formed by Agaddition.

Around $220-250{ }^{\circ} \mathrm{C}$, endothermal peak (peak B) is observed in both alloys. It suggests that nanoclusters are dissolved into matrix of the alloys at around $220-250{ }^{\circ} \mathrm{C}$. In Ag-added alloy, there are almost no endothermal peaks in the as-quenched condition. After aging for several times, endothermal peak is observed however the area of the peak is smaller than that of the Base alloy, suggesting that thermal stability of nanoclusters is improved by the addition of $\mathrm{Ag}$. Above $350{ }^{\circ} \mathrm{C}$, exothermal peaks appear in both alloys. According to the microstructural observation by TEM (section 3.4), peak $\mathrm{C}$ in the Base and Agadded alloy respectively due to another precipitate formation. Peak $\mathrm{D}$ is assumed to due to the formation of $\mathrm{S}$ phase. It is considered that in the Ag-added alloy, even the amount of precipitates is much smaller than that of the Base alloy, the shape, size and distribution of precipitates are extremely appropriate to improve the age-hardenability of the alloy. The detail of microstructure of both alloys will be discussed in next section.

\subsection{Microstructure Investigation}

Figures 7 and 8 show microstructures for the Base and Ag-added alloys aged at $170^{\circ} \mathrm{C}$. 


\subsubsection{Base Alloy}

Figure 7 shows TEM microstructures for the Base alloy aged at $170^{\circ} \mathrm{C}$ for various aging times. During the plateau stage of hardening (Fig. 7(a)), there is no clear evidence of any precipitates. On the other hand, the microstructures at the end of plateau stage consist of rod-shaped Guinier-Preston-Bagaryatsky (GPB) zones and the lath-shaped S' (or S) phase (Fig. 7(b)). At the peak hardness, a large amount of the S' phase are heterogeneously observed on dislocations (Fig. 7(c)). It is suggested that the strengthening phase at the second hardening stage is $S^{\prime}$ (or $S$ ) phase in the Base alloy. Also square cross section of unknown phase is observed. In Fig. 7(c), there are (i) GPB zones, (ii) S' phase and (iii) unknown phase. HAADF-STEM analysis revealed the structure of the unknown phase (Fig. 9). The phase has cubic structure and we identified it as Z phase [11].Figure 10 shows Nanobeam electron Diffraction (NBD) patterns (a) along precipitate needle length and (b) perpendicular to the needle for the phase. Those patterns doesn't fit with the diffraction pattern of $T$ phase but fit with those of $Z$ phase. $Z$ phase was first reported by Chopra et al. [11]. It was found in overaged $\left(2400\right.$ hours at $\left.170{ }^{\circ} \mathrm{C}\right) \mathrm{Al}-1.5 \mathrm{wt} \% \mathrm{Cu}-4.0 \mathrm{wt} \% \mathrm{Mg}-0.5 \mathrm{wt} \% \mathrm{Ag}$ alloy. It has been known that trace addition of $\mathrm{Ag}$ promotes fine distributed precipitate of $\mathrm{Z}$ phase in $\mathrm{Al}-\mathrm{Cu}-\mathrm{Mg}$ ternary alloys [12] however it was found in Ag-free alloy in this study. In this study, Z phase appeared after the prolonged aging and it might contribute to increase the hardness of the Base alloy. On the other hand, the origin of the first rapid hardening has not been clearly observed. It is considered that the rapid hardening is attributed to solute clustering rather than to the formation of GPB zones or Z phases. This rapid hardening phenomenon (RHP) has been termed as "cluster hardening" [13, 14]. However some researchers propose the dislocation-solute atom interaction $[15,16]$ as the origin of RHP. And some researchers reported that the $\mathrm{S}$ phase which nucleates heterogeneously on dislocations is responsible for the rapid hardening [17]. There is still no unified interpretation.

\subsubsection{Ag-Added Alloy}

Figure 8 shows TEM microstructures for the Ag-added alloy aged at $170^{\circ} \mathrm{C}$ for various aging times. The trace addition of $\mathrm{Ag}$ drastically changes the microstructure. In contrast to the Base alloy, fine distributed precipitates were obtained from the beginning of age-hardening (Fig. 8(a)). At the peak hardness (Fig. 8(b)), dense and homogeneous distribution of fine particles is obtained. The dispersed precipitates are present here as the major constituent although lath-shaped S' (or S) phase has not appeared after prolonged aging (Fig. 8(c)). HAADF-STEM of the precipitates indicates disorder (Fig. 11(a)). FFT from local regions (here Al $\langle 112\rangle$ zone), shows 5-fold intensity distribution (Fig. 11(b)). The IFFT shows they could be overlaid by periodic stacks of pentagons, reminiscent of the Laves T-(Mg32(Al, Ag)49) phase (Fig. 11(b))18). BIt was found that by small addition of $\mathrm{Ag}$, formation of $\mathrm{T}$ phase is promoted this phase contributes to improve age-hardenability of $\mathrm{Al}-\mathrm{Mg}-\mathrm{Cu}$ alloy. The mechanical properties of $\mathrm{Al}-\mathrm{Mg}-\mathrm{Cu}$ alloy will be much improved by controlling optimum alloy compositions and microalloying elements to be more suitable in the industrial process.

The precipitation sequence leading to the formation of $\mathrm{S}$ phase is well investigated in $\mathrm{Al}-\mathrm{Mg}$-Cu based alloys. In contrast, the precipitation sequences of the $\mathrm{T}$ and $\mathrm{Z}$ phase are less clear. The BCC $\mathrm{T}$ phase $\left(\mathrm{Mg}_{32}(\mathrm{Al}, \mathrm{Zn})_{49}\right)$ is known to contain 162 atoms in its unit cell, and 98 of these have nearest neighbor atoms arranged in icosahedral coordination shells. Both the $\mathrm{T}$ and the $\mathrm{Z}$ phases possess a periodic icosahedral arrangement in contrast with the quasiperiodic icosahedral arrangements $[18,19]$. The formation mechanism of the $\mathrm{Z}$ phase and the structural correlation between the $T$ phase and the $\mathrm{Z}$ phase remain to be fully understood. In this study, individual precipitates of the $\mathrm{Z}$ and $\mathrm{T}$ phases have been found in the $\mathrm{Al}$ $\mathrm{Mg}-\mathrm{Cu}$ and $\mathrm{Ag}$-added alloys respectively.

$\mathrm{Al}-\mathrm{Cu}-\mathrm{Mg}$ system, trace addition of $\mathrm{Ag}$ promotes formation of three new and quite different precipitates depending on the $\mathrm{Cu}: \mathrm{Mg}$ ratio (Table 3) $[11,12,20]$. However those alloys contain impurity elements such as $\mathrm{Mn}, \mathrm{Fe}$ and $\mathrm{Si}$ and the alloys which are developed from elemental components of high purity have not been studied well. Those impurity elements might affect the formation behavior of nanoclusters in the initial stage of age-hardening and change precipitate microstructure after prolonged aging. Further investigation is needed. 
Table 3 Details of precipitates formed by the addition of $0.4 \% \mathrm{Ag}$ to aged ternary Al-Cu-Mg alloys. (I. J. Polmear: Light Alloys Fourth Edition (2007))

\begin{tabular}{|c|c|c|c|}
\hline Cu:Mg Ratio & Precipitate & Crystal Structure & \\
\hline High: e.g. Al- $4 \mathrm{Cu}-0.3 \mathrm{Mg}$ & $\Omega$ & orthorhombic & $\begin{array}{l}\mathrm{a}=0.496 \mathrm{~nm} \\
\mathrm{~b}=0.859 \mathrm{~nm} \\
\text { c } 0.848 \mathrm{~nm}\end{array}$ \\
\hline Medium: e.g. Al-2.5Cu-1.5Mg & $X^{\prime}$ & c.p. hexagonal & $\begin{array}{l}\text { a } 0.496 \mathrm{~nm} \\
\text { c } 1.375 \mathrm{~nm}\end{array}$ \\
\hline Low: e.g. Al-1.5Cu-4.0Mg & Z & cubic & $\mathrm{a}=1.999 \mathrm{~nm}$ \\
\hline
\end{tabular}

(a)

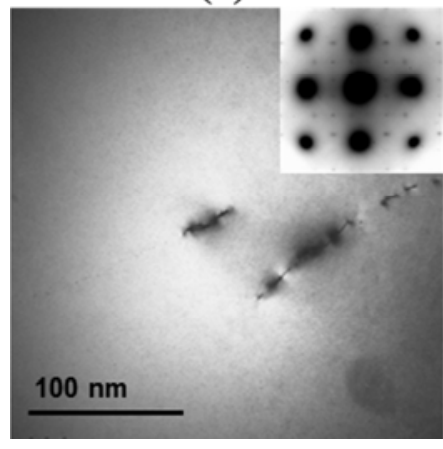

(b)

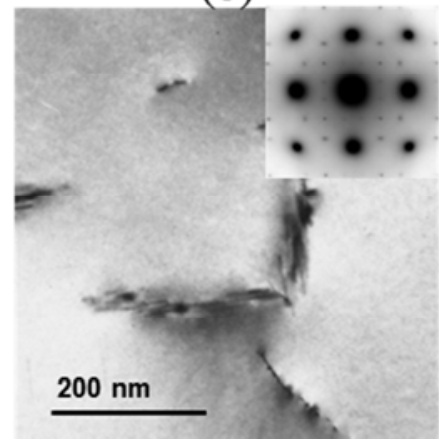

(c)

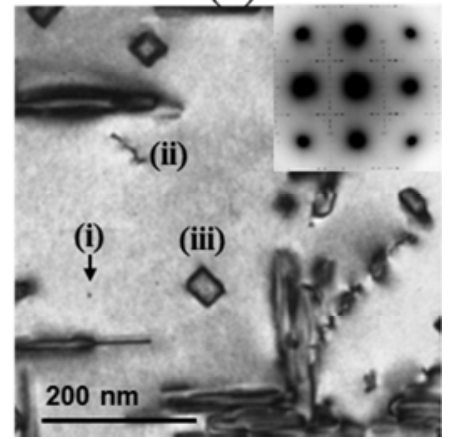

Fig. 7. Bright field TEM images with diffraction patterns taken along $\langle 001\rangle$ Al for the Ag-added alloy aged at $443 \mathrm{~K}$ for (a) $10.8 \mathrm{ks}$ (b) $432 \mathrm{ks}$ and (c) $950.4 \mathrm{ks}$.

(a)

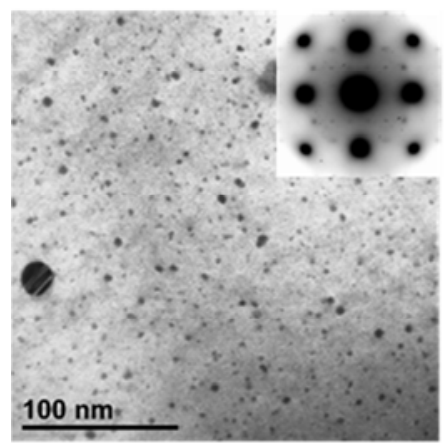

(b)

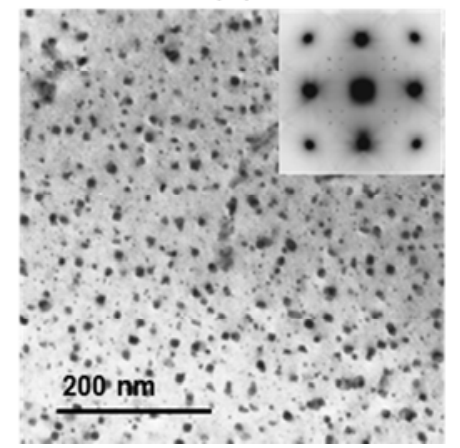

(c)

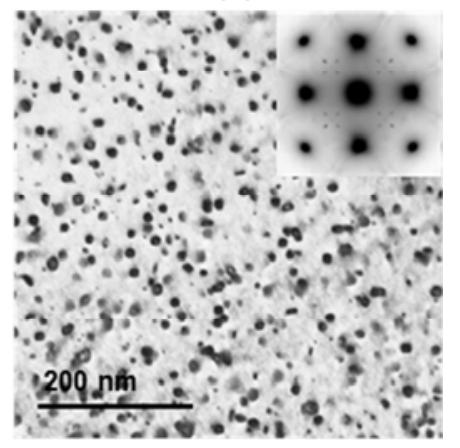

Fig. 8. Bright field TEM images with diffraction patterns taken along $\langle 001\rangle \mathrm{Al}$ for the Base alloy aged at $443 \mathrm{~K}$ for (a) $10.8 \mathrm{ks}$ (b) $86.4 \mathrm{ks}$ and (c) $950.4 \mathrm{ks.}$

(a)

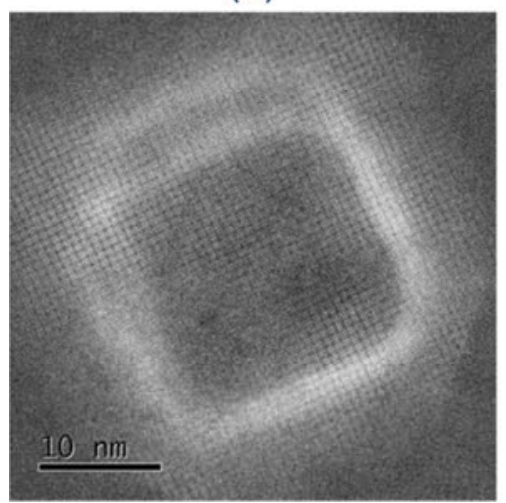

(b)

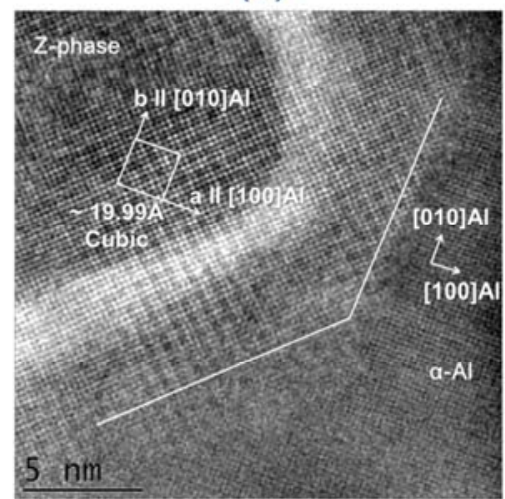

Fig. 9. HAADF-STEM images of $\mathrm{Z}$ phase taken along $\langle 001\rangle \mathrm{Al}$ for the Base alloy aged for $950.4 \mathrm{ks}$ at 443 K.NBD patterns (a) along precipitate needle length and (b) perpendicular to the needle for $Z$ phase in the Base alloy aged at $443 \mathrm{~K}$ for $950.4 \mathrm{ks}$. 
(a)

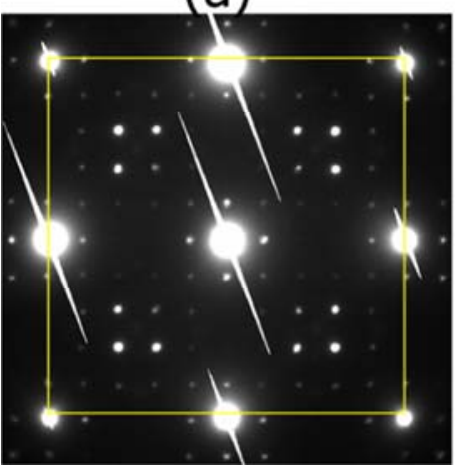

(b)

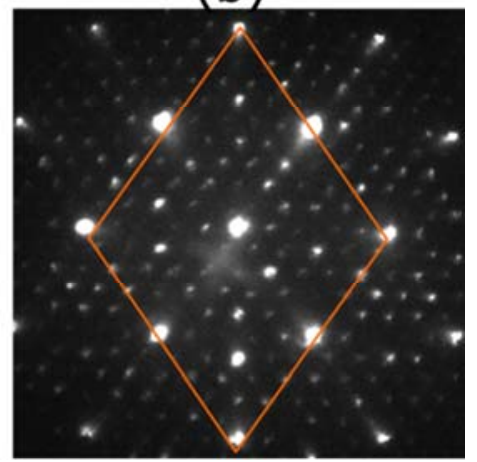

Fig. 10. NBD patterns (a) along precipitate needle length and (b) perpendicular to the needle for $Z$ phase in the Base alloy aged at $443 \mathrm{~K}$ for $950.4 \mathrm{ks}$.

(a)

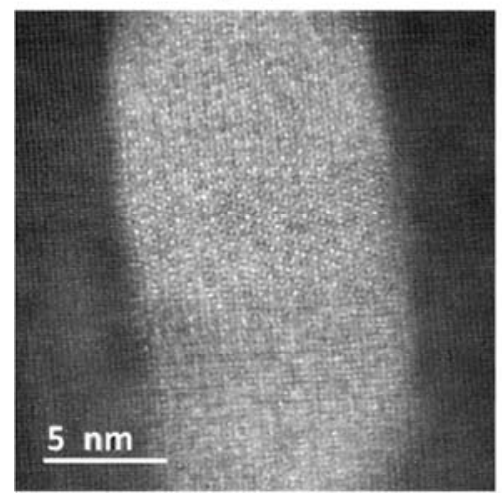

(b)

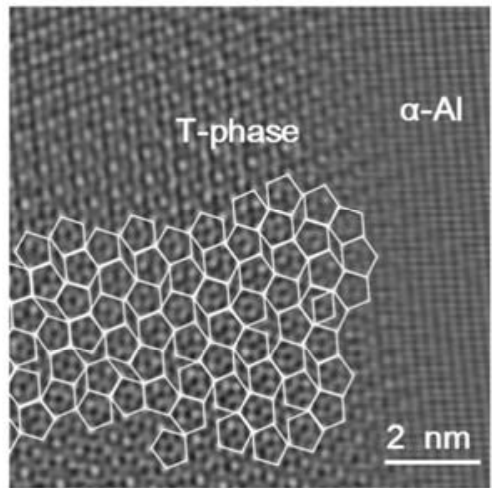

Fig. 11. (a) HAADF-STEM image and (b) the atomic structure of the $\mathrm{T}$ phase in $\langle 112\rangle \mathrm{Al}$ in Ag-added alloy aged at $443 \mathrm{~K}$ for $950.4 \mathrm{ks}$. The image was filtered using Fast Fourier transform (FFT) filtering to reduce noise using a circular band pass mask that removed all periods shorter than $\mathrm{nm}$.

\section{Conclusion}

Age-hardening response of the $\mathrm{Al}-\mathrm{Mg}-\mathrm{Cu}(-\mathrm{Ag})$ alloys was investigated using hardness measurement and TEM observation. The obtained results are summarized as follows:

(1) The Al-Mg-Cu alloy shows three stages of age-hardening reactions, the first hardening stage, plateau stage and second hardening stage. It is understood that the first, plateau and second stages are attributed to the nanocluster formation, the incubation period and the formation of precipitates $\left(S^{\prime}\right.$ or $S$ phase), respectively.

(2) In the Ag-added alloy, a dense distribution of fine precipitates of the $\mathrm{T}$ phase is observed from the beginning of the age-hardening. By small addition of $\mathrm{Ag}$, formation of $\mathrm{T}$ phase is promoted and agehardening response is much improved.

\section{Acknowledgement}

The present research was partially supported by the Light Metal Educational Foundation, Inc and Japan Aluminium Association Research Grant Program.

\section{References}

[1] Y. Suzuki, M. Matsuo, M. Saga, and A. Kikuchi, "Properties of bake hardenable Al-Mg-Cu alloy sheets," in 5th Int. Conf. on Aluminum Alloys, Grenoble, France, pp. 1789-1794, 1996.

[2] Y. A. Bagaryatsky, "Structural changes on aging Al-Cu-Mg alloys," Dokl. Akad. SSSR 87, pp. 397-401, 1952. 
[3] J. M. Silcock, "The structural ageing characteristics of Al-Cu-Mg alloys with copper: magnesium weight ratios of 7:1 and 2.2:1," J. Inst. Met., vol. 89, pp. 203-210, 1960.

[4] C. Li, G. Sha, B. Gun, J. H. Xia, X. F. Liu, Y. Y. Wu, N. Birbilis, and S. P. Ringer, "Enhanced agehardening response of Al-4Mg-1Cu (wt.\%) microalloyed with Ag and Si," Scripta Materialia, vol. 68, p. 857, 2013.

[5] C. Li, G. Sha, J. H. Xia, B. Gun, L. Li, J. Z. Cui, X. F. Liu, and S. P. Ringer, "Effect of solution treatment on precipitation and age-hardening response of an $\mathrm{Al}-4 \mathrm{Mg}-1 \mathrm{Cu}-0.5 \mathrm{Si}-0.4 \mathrm{Ag}$ (wt $\%$ ) alloy," Mater. Sci. Engineering A, vol. 599, pp. 64-68, 2014.

[6] I. J. Polmear, and S. P. Ringer, "Microstructural evolution and age hardening in aluminium alloys," J. Jpn. Inst. of Light Metals, vol. 50, pp. 633-642, 2000.

[7] S. Hirosawa, "Development of Al based alloys by microalloying elements," Proc. of the 4th Japanese-Polish Joint Seminar on Materials Analysis, pp. 27-28, 2002.

[8] T. Sato, S. Hirosawa, K. Hirose, and T. Maeguchi, "Roles of microalloying elements on the cluster formation in the initial stage of phase decomposition of Al-based alloys," Metallurgical and Materials Transactions A, vol. 34, pp. 2745-2755, 2003.

[9] S. Hirosawa, T. Omura, Y. Suzuki, and T. Sato, "Effects of Ag addition on Age-hardening and nanoscale precipitate microstructures of an $\mathrm{Al}-3.0 \% \mathrm{Mg}-1.0 \% \mathrm{Cu}$ alloy," J. Jpn. Inst. of Light Metals, vol. 56, pp. 673-679, 2006.

[10] Y. Suzuki, A. Hibino, T. Muramatsu, S. Hirosawa, and T. Sato, "Bake-hardenability of Al-Mg-Cu-X (Ag,Zn,Si) alloy sheets," 9th Int. Conf. of Aluminum Alloys, Brisbane, Australia, pp. 258-263, 2004.

[11] H. D. Chopra, B.C. Muddle, and I. J. Polmear, "The structure of primary strengthening precipitates in an Al-1.5wt\% Cu-4.0wt\% Mg-0.5wt\% Ag alloy," Phil. Mag. Lett., vol. 73, pp. 351-357, 1996.

[12] I. J. Polmear, Light Alloys, 4th ed., 2007.

[13] S. P. Ringer, T. Sakurai, and I. J. Polmear, "Origins of hardening in aged Al-Cu-Mg-(Ag) alloys," Acta mater, vol. 45, pp. 3731-3744, 1997.

[14] S. P. Ringer, S. K. Caraher, and I. J. Polmear, "Response to comments on cluster hardening in an aged Al-Cu-Mg alloy," Scripta Materialia, vol. 39, pp. 1559-1567, 1998.

[15] L. Reich, S. P. Ringer, and K. Hono, "Origin of the initial rapid age hardening in an Al-1.7 at. \% Mg1.1 at.\% Cu alloy," Phil. Mag. Lett., vol. 79, pp. 639-648, 1999.

[16] Y. Nagai, M. Murayama, Z. Tang, T. Nonaka, K. Hono, and M. Hasegawa, "Role of vacancy-solute complex in the initial rapid age hardening in an Al-Cu-Mg alloy," Acta mater., vol. 49, pp. 913-920, 2001.

[17] P. Ratchev, B. Verlinden, P.de Smet, and P.van Houtte, "Effect of cooling rate and predeformation on the precipitation hardening of an Al-4.2wt.\%Mg-0.6wt.\%Cu alloy," Scripta Materialia, vol. 38, pp. 1195$1201,1998$.

[18] M. Kubota, J. F. Nie, and B. C. Muddle, "Characterisation of quasicrystalline particles in an isothermally aged $\mathrm{Al}-10 \mathrm{Mg}-0.5 \mathrm{Ag}$ (mass\%) alloy," Materials Transactions, vol. 46, pp. 1278-1287, 2005.

[19] M. Duneau, and A. Katz, "Quasiperiodic patterns," Phys. Rev. Lett., vol. 54, pp. 2688-2691, 1985.

[20] H. D. Chopra, B.C. Muddle, and I. J. Polmear, "The structure of metastable $\{111\} \alpha$ precipitates in an Al-2.5wt\%Cu-1.5wt\%Mg-0.5wt\%Ag alloy," Phil. Mag. Lett., vol. 71, pp. 319-324, 1995. 